\title{
A tradição do milho: o ingrediente base da cozinha caipira e das festas juninas
}

\author{
CORN TRADITION: THE BASE INGREDIENT OF COUNTRY SIDE COOKERY AND JUNE BONFIRE PARTIES
}

Suely Sani Pereira Quinzani

Centro Universitário N.S. Patrocinio - CEUNSP - Itu - São Paulo - Brasil

Tatiana Caroline Silveira Corrêa

Estudiosa das áreas de gastronomia italiana e brasileira - Itu - São Paulo - Brasil

Daniela Vilela Peixoto

Centro Universitário N.S. Patrocinio - CEUNSP - Itu - São Paulo - Brasil

\section{Ana Alice Silveira Corrêa}

Centro Universitário Senac -Itu - São Paulo - Brasil

\begin{abstract}
Resumo: A intenção deste trabalho é mostrar que o ingrediente milho une cultura e culinária caipiras às tradições das festas juninas paulistas. A festa junina tem como base a figura do caipira, homem simples dos campos paulistas cujos traços, roupas, trejeitos e linguajar simbolizam o tipo junino clássico de se vestir e de se sentir caipira. E a doçaria desta festa brasileira tem a mesma base da tradicional cozinha paulista que se sustenta principalmente no milho. Quando se conceitua a cozinha caipira, aquela que é denominada simples, saborosa e de "sustância" percebe-se que, mesmo com o passar dos tempos, o milho, cereal base da alimentação dos movimentos bandeirante e tropeiro, está sempre presente no cotidiano do caipira e nas suas vivências culturais, aglutinando-se nos quitutes desta festa como seu elemento substancial e essencial. Quando se estabelece o conceito de tradição, percebe-se, que ela se caracteriza pela continuidade e invariabilidade dos atos praticados no passado. Embora essa festa tenha suas raízes no cristianismo, tendo sido trazida pelo colonizador português, a tradição das festas juninas tem a função de dar resistência às inovações e assim estabelecer a importância de se cultuar o passado. Como metodologia para o trabalho, utilizou-se a pesquisa exploratória com levantamentos bibliográficos em busca de fatos e dados históricos e contemporâneos sobre a figura do caipira, sua cultura e sobre o ingrediente milho como base da doçaria típica das festas juninas. Os dados encontrados foram analisados através do método descritivo.
\end{abstract}

Palavras-chave: Milho. Cozinha caipira. Festas juninas.

Abstract: The present work goal is to display that the corn, as an ingredient, gather both culture and culinary to the traditional country party in the state of São Paulo. This country party is based on the figure of the farmer, the homely man from the fields, whose features, clothing, manners and speech are all symbols represented in the costumes of the classic June country party. Also, the confectionery typical of this June country party is based on the same recipes of the paulista cookery, which base is the corn. When the country cookery is nominated, the one which is denominated as simple, tasteful and "hearty", one can note that, even through time, the corn, that served as base of the food for those Portuguese, who first entered the unexplored Brazil country side, is always present on daily meals of nowadays country man, being also center element of the confectionery. Taking the concept of tradition, it is noticeable that it involves continuity and uniformity of acts from the past. Although this party has its roots in the Christianity, had been brought to Brazil by the Portuguese, June bonfire party tradition also has the role to display resistance to new habits, imposing the importance to worship the past. Methodology for this work include exploratory research through bibliographic registers searching for both historical and contemporary facts and data about the figure of the typical Brazilian farmer, their culture and about the use of corn as a base ingredient for the June country party confectionery. Data were analyzed through the descriptive method.

Keywords: Corn. Countryside cookery. June bonfire party. 


\section{Introdução}

Ao pensar em tradição, cultura alimentar, cultura caipira, nada parece mais antigo e conectado ao passado dos paulistas do que comidas à base de milho. Religar elementos culturais das festas juninas e seus representativos doces com base no ingrediente milho, é reviver a tradição da cozinha caipira.

Uma tradição não deve ser confundida com costume mas deve ser entendida como as regras tácitas ou abertamente aceitas, cujas práticas de natureza ritual ou simbólica visam repetir seguidamente, no espírito de um povo, valores e normas de comportamento implicando uma "continuidade" em relação ao passado (HOBSBAWN,2014).

O filósofo Gerd Bornheim (1997) observa que a palavra tradição vem do latim, traditio, verbo tradire, que designa o ato de passar algo para outra pessoa, ou, passar de geração para outra geração. Isto faz com que a tradição seja compreendida como o conjunto de valores dentro dos quais estamos estabelecidos, não se tratando apenas das formas de conhecimento ou de opiniões, "mas também da totalidade do comportamento humano, que só se deixa elucidar a partir do conceito de valores constitutivos de uma determinada sociedade" (BORNHEIM,1997, p.20).

Esta é a justificativa deste trabalho que une o milho, a cultura, a culinária caipira e a tradição das festas juninas, "a mais brasileira das festas," tão enraizadas nos hábitos tradicionais dos paulistas.

A festa junina tem como base a figura do caipira, o homem simples que habitava os campos paulistas cujos traços, roupas, trejeitos e linguajar simbolizam até hoje o tipo junino clássico de se vestir e de se sentir caipira, seguindo uma tradição que vem do personagem Jeca Tatu de Monteiro Lobato. Ao ser analisado no seu modo de ser, dá representatividade a alguns costumes ligados à roça e estereotipados no seu jeito simplório de ser, que se mesclam a certezas divinas, provindas de uma religiosidade intensa e relações sociais de compadrio típicas do interior paulista.

Desta forma, estabelece-se que, tanto a doçaria desta festa brasileira, como outros muitos pratos típicos, tem a mesma base da tradicional cozinha paulista que se sustenta principalmente no milho. Hábitos alimentares devem ser entendidos como "meios pelos quais os indivíduos, respondendo a pressões sociais e culturais, selecionam, consomem e utilizam porções dos conjuntos de alimentos disponíveis" (MEAD e GUTHE, 1945 apud BLEIL, 1998, p.2) e, no caso de São Paulo, esses hábitos se sustentam no consumo do milho e seus derivados.

E entre toda a representatividade desta festa com balões, fogueiras, danças, música, a comida, notadamente, dá suporte a toda essa alegria, fazendo presente a tradição da cozinha paulista. Essa cozinha tradicional e as festas juninas, quando analisadas, estabelecem uma forte conexão com o gosto alimentar do Estado de São Paulo desde os primórdios da conquista dos campos de Piratininga.

Ao estabelecer-se o conceito de tradição, percebe-se que ela se caracteriza pela continuidade e invariabilidade dos atos praticados no passado. Com base em "costumes dos tempos imemoriais", porque esta festa tem suas raízes no cristianismo e foi trazida para o Brasil pelo colonizador português, a tradição das festas juninas tem a função de dar resistência às inovações, reforçando a importância de se cultuar o passado.

De acordo com Reinhardt (2007) uma tradição culinária constitui um saber-fazer transmitido entre gerações e cujos significados, dentro da dinâmica cultural, podem ser adaptados sem que percam características e conteúdos que os tornaram reconhecidos como tradição.

O antropólogo Sidney Mintz (2001 p.32) defende que os hábitos alimentares "podem mudar inteiramente quando crescemos, mas a memória e o peso do primeiro aprendizado alimentar e uma das formas sociais aprendidas através dele permanecem, talvez, para sempre em nossa consciência". 
Quando se conceitua a cozinha caipira, aquela que é denominada simples, saborosa e de "sustância" percebe-se que, mesmo com o passar dos tempos, o milho, cereal base da alimentação dos movimentos bandeirante e tropeiro, está sempre presente no cotidiano do caipira e nas suas vivências culturais, aglutinando-se na doçaria desta festa como seu elemento substancial e essencial.

Utilizando-se de vasto acervo bibliográfico de natureza exploratória, através de reflexão sobre o assunto e tendo como base autores como Rosa Belluzzo, Antônio Cândido, Cornélio Pires, Maria Alice Setúbal entre outros, problematizou-se o tema. Desta forma será analisada a tradição das festas juninas, sua intima relação com a figura do caipira, sua cultura alimentar e o milho, ingrediente base da doçaria típica.

\section{O CAIPIRA, A FESTA, O MILHO E AS COMIDAS}

\subsection{Como se define o caipira}

Para se analisar este tema é necessário entender que a tradição, costumes e certos comportamentos sociais precisam ser recuperados para o esclarecimento desta questão.

Antes de se cozinhar, de se colocar uma panela no fogo, é necessário entender a comida como uma expressão cultural. Refletir sobre a alimentação como um fenômeno cultural é ultrapassar a questão da simples necessidade fisiológica, englobando significados, costumes e comportamentos.

Culturalmente, de acordo com Bonin e Rolim (1991, P.76), "os hábitos alimentares se traduzem na forma de seleção, preparo e ingestão de alimentos que não são o espelho, mas se constituem na própria imagem da sociedade".

De acordo com Poulain (2013), a cultura alimenta e as práticas alimentares são "marcadores identitários" pelos quais se desenvolvem códigos de diferenciação social e que são verdadeiros objetos sociais. A culinária e as maneiras à mesa são atividades sociais que se desenvolvem num espaço deixado livre por um conjunto de condicionantes materiais: ecológicas, tecnológicas e biológicas. A alimentação tem uma função estruturante da organização social de um povo.

É nesse sentido que podemos definir a questão de ser caipira no estado de São Paulo e todas as circunstâncias de suas preferências culturais, alimentares e sociais que determinam o mundo caipira.

Caipira, palavra pejorativa dos tempos atuais, que estereotipa o homem simplório que possui hábitos simples e essencialmente deselegante, desajeitado, para alguns, fala errado, mas, na verdade, é um grande observador das coisas simples e, por isso mesmo, despreparado para o convívio nas cidades. Este homem, o caipira, é o elemento representativo de uma cultura, a paulista.

Este personagem, nascido no interior das terras paulista, é quem dá alma a estas festas denominadas juninas, emprestando sua caracterização própria e desajeitada para que, à época do mês de junho, possa-se reviver o homem rural dos tempos de outrora. Segundo Chianca (2010), além da "fantasia" baseada no caipira paulista, o milho, a fogueira e a quadrilha compõem os quatro elementos que marcam as festas juninas.

Mas, quem é o caipira?

Caipira, etimologicamente, vem do tupi guarani, "kai-ñ-pirá, ou seja, aquele homem que à época da colonização se sediou no interior das terras paulistas em contraposição ao "kai-ñ-çará" que se sediou no litoral paulista (SANCHES, 2011).

Nascido da miscigenação racial do índio brasileiro com o português colonizador, era homem livre e simples que nada possuía de seu além da liberdade e traços marcantes de sua origem indígena.

Mencionado no livro "Viagem à Província de São Paulo", Saint-Hilaire (1976) define esses paulistas como oriundos das capitanias hereditárias, também conhecidos como vicentinos por serem provenientes da capitania de São Vicente. Chegaram às terras paulistas nos meados do século XVI. Nessa época, desenvolviam a cultura da cana de açúcar 
cujo cultivo não teve sucesso na faixa litorânea da Província de São Paulo. Em razão desse fato, essa população que habitava o litoral paulista dividiu-se em dois grupos, os que seguiram serra abaixo e os que seguiram serra acima em direção ao interior, os caipiras.

Saint-Hilaire (1976) ainda define esse homem como um tipo rudimentar, de poucas falas que habitava casebres e que possuía pouca polidez. Para ele era um homem do interior paulista que povoava as grandes extensões de terra sem dono, que não se importava muito com a construção de sua casa e só plantava o necessário, como o feijão e o milho. Não plantava alimentos que demandassem tempo para a colheita, pois como não era dono das terras, corria o risco de tudo perder.

Portanto, pode-se concluir que o caipira se alimentava principalmente de milho, da sua farinha e feijão. Utilizava também a farinha de mandioca. Só muito tempo mais tarde é que o arroz entra em sua composição alimentar. Ao lado desses alimentos, ainda utilizava a abóbora, o cará, a batata doce, carnes de caça e peixes, frutas e os doces das mesmas.

O milho, no entanto, era muito presente em sua alimentação. Utilizado assado ou cozido, além de utilizar o suco dos seus grãos verdes para a feitura de curais e pamonhas.

Desta forma, garantia-se com esta lavoura de subsistência a sobrevivência nos campos do planalto de Piratininga. Paula Pinto e Silva (2005) estabelece que o milho e seus derivados como biscoitos, bolos de fubá e melado, as pamonhas e curau eram parte da dieta cotidiana dos paulistas. Antônio Cândido (1987) corrobora a mesma opinião quando estabelece que os diversos pratos preparados com milho determinavam a invenção e adaptação deste cereal conhecido dos índios, onde se podia utilizar técnicas simples de preparo emprestadas dos nativos e adequadas ao estilo de vida rústica e itinerante dos moradores de Piratininga.

Além da maneira simples e peculiar de se alimentar, o caipira paulista possuía um estilo de vida próprio. De acordo com Antônio Cândido (1975), o caipira sugere um "modo de ser, um estilo de vida", portanto, é possuidor de uma cultura própria e definida.

Desta cultura caipira, podemos citar seu linguajar próprio, muito forte no sotaque e no uso do $\mathrm{R}$ retroflexo, fala mansa com vocábulos no diminutivo que acabaram permeando o contexto caipira na prosa, poesia e música. Seu modo de vestir, também peculiar e sui generis baseava suas vestimentas em algodão grosseiro tanto para homens como mulheres. O algodão era colhido e fiado em casa mesmo e o pano era tecido em tear emprestado de algum tecelão da vizinhança. Suas vestes compunham-se de calça e camisa para os homens e blusa e saias compridas para as mulheres. O tingimento dos tecidos era caseiro e geralmente em cores escuras como o marrom e o acinzentado (SANCHES, 2011).

Seus maiores lazeres, além de pescar e caçar, eram cantar e dançar. Porém é na religiosidade que o caipira se fortalece. De acordo com Setubal (2005) essa religiosidade fortalece o rural do urbano e a crença na Virgem Maria e nos Santos católicos orienta a sua vida.

A sua fé, determinava em Santo Antônio a benção para 0 alimento na mesa e para os casamentos; em São João, a proteção do plantio e da colheita e em São Pedro a benção para entrar nos reinos do céu (SANCHES, 2011).

De acordo com Antônio Candido (1975) essas expressões religiosas e musicais davam-se geralmente à época de boas colheitas onde, para pagar a promessa a seu santo de devoção, convocava seus vizinhos para os devidos agradecimentos. Ainda de acordo com o autor, o caipira vivia isolado, mas, próximo de "bairros", ou seja, ao núcleo da comunidade próxima à sua casa e roça.

Certamente, vem daí, o inicio das tradicionais festas juninas paulistas, na junção da cultura caipira com os elementos comestíveis, vestes, falas, música e religiosidade.

Atualmente, de acordo com Chianca (2010), a aproximação do mês de junho, faz os cidadãos urbanos procurarem reviver o "modo de vida caipira" 
nas festas juninas onde, de modo alegre, se festeja esse momento especial do calendário nacional, degustando-se todas as guloseimas de pratos típicos e especiais. A autora também reforça que em todo território nacional essa "festa rural" permite a atualização da imagem e da identidade do homem do campo onde, através de uma reflexão sócio antropológica, pode-se analisar alguns pontos delineados na tradição dessas festas como vestimentas, quadrilha e a apropriação da figura do caipira e do seu modo de se alimentar. Outro aspecto é a análise da questão das vestimentas que define o caipira na sua mais pura simplicidade e revela a sua condição sócio econômica, marcando uma ligação do passado com o futuro.

Por outro lado, ele reforça o estereótipo citadino do homem do campo: cores fortes e disparatadas, maquiagem simulando dentes em falta e cicatrizes grosseiras, além de sobrancelhas, barbas e bigodes reforçados, compondo uma imagem mais "selvagem" do matuto. As festas juninas marcam o único momento do ano em que vestimentas de pais e avós são publicamente recuperadas, indicando a relação com o passado que se deseja revisitar: retomar as roupas de família parece ser um modo de recuperar a identidade de migrante com o intuito de melhor ultrapassá-la no contexto derrisório da festa (CHIANCA, 2010, p.1).

\subsection{A festa e sua evolução através dos tempos}

Pode-se dizer que a comida tem sempre significados fundamentais à identidade de um povo. Pode-se dizer também que a comida é algo de extrema importância, tanto quanto a língua utilizada para se expressar num determinado grupo social ou nação. Portanto, comer caracteriza e distingue sociedades traçando o que é cultural a essas pessoas, pois, tudo o que comemos está ligado a usos, costumes e tradições.

No que tange as tradições, entre outros requisitos que define o que é tradicional para um povo, festa e festejar, para os brasileiros são as mais expressivas representações de tradição do que somos como povo.
No caso das festas juninas, elas constituem um grande ritual alegre e festivo que celebra o louvor aos santos padroeiros e que têm sua representatividade expressa em todo território nacional, sobretudo no nordeste e sudeste do Brasil.

O festejo do que hoje entendemos por festas juninas é ancestral. Remonta a tempos imemoráveis, a um tempo muito antigo, anterior ao surgimento da era cristã

De acordo com Rangel (2008) em menção ao livro de sir James George Frazer (1978), o mês de junho, início do solstício de verão no Hemisfério Norte, povos como celtas, bretões, bascos, sardenhos, egípcios, persas, sírios, sumérios faziam rituais de invocação de fertilidade para estimular o crescimento da vegetação, promover a fartura nas colheitas e trazer chuvas.

Esses rituais de fertilidade associados ao cultivo das plantas, ou seja, a preparação do terreno, o plantio e a colheita, sempre foram praticados nas terras do Mediterrâneo oriental com o objetivo de regular as estações do ano, especialmente a passagem da primavera para o verão que é a superação da passagem do inverno (FRAZER, 1978 apud RANGEL, 2008).

Os rituais da fertilidade perduraram através dos tempos e, na era cristã, mesmo que fossem considerados pagãos, não era mais possível acabar com eles; por esse motivo, a Igreja Católica, em vez de condená-los, os adapta às comemorações do dia de São João que teria nascido em 24 de junho, dia do solstício de verão.

Outra coincidência também é determinada pelo propósito católico de atrair os índios ao convívio missionário de catequização e suas práticas rituais, simbolizadas pelas fogueiras de São João.

A questão da sociabilidade entre as populações rurais é outro ponto a se considerar, já que, de acordo com Rangel (2008), 70\% da população brasileira, até meados do século $X X$, viviam no campo; as famílias brasileiras viviam integradas a seus grupos familiares (pais, filhos, tios, avós, etc.) e ligadas também à instituição do compadrio e do trabalho em mutirão. O compadrio, ou 
seja, os laços advindos do compadre, comadre, padrinho e madrinha, serviam de estreitamento do convívio entre vizinhos, patrões, empregados e familiares.

Essas características culturais da sociedade caipira organizada em bairros rurais como define Candido (1975) em seu livro Parceiros do Rio Bonito, estabelecia que cada família tinha sua roça ou rocinha e alguma criação totalmente direcionada ao seu sustento. Corrobora com esta opinião, o historiador lanni (1988) quando em seu livro "Uma cidade antiga" aborda a questão da colheita na roça. $\mathrm{Na}$ roça trabalham os homens e as mulheres, os adultos e as crianças, conforme a precisão, tanto para uma colheita como na construção de uma casa; os vizinhos, amigos ou parentes do bairro participam no ajutório. Esses trabalhos sociabilizados em forma de mutirão aliado a fortes elementos religiosos da cultura caipira ressaltam, por exemplo, as festas juninas. Tratava-se de festas nas quais as famílias do bairro e de bairros próximos ou distantes, comemoravam o início ou fim de um ciclo agrícola ou o padroeiro do lugar: Santo Antônio, São Pedro e São João.

Havia bairros rurais que se empenhavam na organização e no brilho da festa de São João; outros na de São Pedro; e assim por diante.

Rangel (2008) estabelece que o compadrio era obtido por duas formas, o batismo e a fogueira. A primeira, muito comum e utilizada até hoje, consiste em se dar em batismo uma criança a um padrinho/madrinha que possa, eventualmente, substituir os pais na ausência ou morte destes. A outra, pela fogueira quando, nas festas de São João, os homens formavam duplas de compadres de fogueira para pagamento sobretudo de promessas.

Dada a sua imensa devoção religiosa, o caipira paulista sempre pagava suas promessas sociabilizando com a família, compadres, afilhados agradecendo às boas coisas e farturas de colheitas obtidas (CÂNDIDO, 2001).

E é desta forma que os Santos Antônio, João e Pedro entram em cena na cultura caipira. Deve-se também relacionar nesta oportunidade o que cada Santo representa em termos de "milagres e promessas". De acordo com as tradições, Santo Antônio é um dos santos de maior devoção no Brasil. Considerado santo familiar e protetor dos varejistas em geral, é também o padroeiro de povoações e soldados. É a ele também que as moças casadeiras pedem um noivo, constituindo tradição colocar o santo de cabeça para baixo no sereno, amarrado num esteio, ou de jogá-lo no fundo do poço até que o pedido seja atendido. É também o único dos santos juninos feito de madeira e em geral é esculpido em nó de pinho (RANGEL, 2008).

Já São João ocupa lugar de destaque, uma vez que é seu nome que origina o termo festas joaninas. Dia 24 de junho é o dia de seu nascimento. De acordo com as tradições juninas, São João adormece no dia 24 , pois, se estivesse acordado vendo as fogueiras que são acessas para homenageá-lo, não resistiria e desceria à terra e ela correria o risco de se incendiar (RANGEL, 2008).

São Pedro, o último dos santos juninos, é considerado o protetor das viúvas e dos pescadores. De acordo com Rangel (2008) é denominado "chaveiro do céu" e desta forma, para entrar no céu, é necessário que São Pedro abra as portas. No dia de São Pedro todo aquele que tiver seu nome deve ascender uma fogueira na porta de sua casa e se alguém amarrar uma fita no braço de uma pessoa chamada Pedro, este deve dar um presente. No dia 29 são realizadas grandes procissões marítimas em sua homenagem e em terra, os fogos e o pau-desebo são as atrações de sua festa.

\subsection{0 milho e sua representatividade}

De acordo com Cândido (2001, p.52) o ingrediente milho teria sido o principal alimento de invenção cultural dentro da culinária caipira, quando descreve que, "o milho foi o cereal básico do aborígene e ainda do caipira, mas de formas múltiplas e variadas, mostrando que sobre ele operou mais intensamente o trabalho cultural de invenção e adaptação".

Planta originária da América, o milho, de acordo com a Embrapa (2008), tem seus primeiros 
registros de cultivo a cerca de 7.300 anos em pequenas ilhas próximas ao litoral do México. De acordo com pesquisadores da Universidade do Estado da Flórida, do Museu Nacional de História dos Estados Unidos, do Instituto Smithsonian, do Instituto da República do Panamá e da Universidade de Washington, sua cultura se espalhou rapidamente pelo México onde foi primeiramente domesticado. Depois se espalhou por outras regiões como o Panamá e América do Sul (EMPRAPA, 2008).

O nome milho significa "o sustento da vida". Com várias utilidades como ingrediente alimentar é constante na alimentação diária de grande parte da população mundial. Ainda de acordo com a Embrapa (2008), o cereal na América do Sul é cultivado há cerca de 40 séculos. No Brasil era o principal alimento dos índios guaranis e, com a chegada do colonizador, se incorporou definitivamente à alimentação do brasileiro.

De acordo com os estudos da historiadora Rafaela Basso (2014) as práticas alimentares na São Paulo colonial reforçam a teoria de Sergio Buarque de Holanda (1994) ser o milho o principal alimento da população paulista, onde o autor celebriza o fato com a expressão "civilização do milho". De acordo com Basso (2014, p.79) em suas obras o historiador Sergio Buarque de Holanda defende a "ideia de que a gramínea teria se firmado como base da alimentação dos paulistas, principalmente por causa da mobilidade das expedições sertanistas". Além disso, a simplicidade de seu cultivo e a rusticidade das técnicas para a elaboração de seus subprodutos como o fubá e a quirela evidencia essa predileção na alimentação paulista colonial que se perpetua através dos tempos.

De acordo com Algranti (2011) uma alimentação nasce de uma necessidade e também da pobreza e da carestia alimentar e, ao se observar os comportamentos alimentares dos paulistas, percebese que os produtos consumidos e as combinações obtidas entre eles evidenciam uma cultura alimentar que nasce em função de trocas entre ingredientes e receitas. O milho foi, à época da colonização, o alimento base para a sobrevivência dos paulistas e perpetuou-se na cultura caipira dada a facilidade de plantio, processamento e mobilidade, ou seja, é uma lavoura de produção rápida, não requerendo processo de elaboração complexo para a obtenção de sub produtos como o fubá e a quirela e que permitia o transporte com facilidade e durabilidade. No caso específico do caipira, o milho entra em sua cultura alimentar exatamente pela rápida produtividade dado que não tinha a posse da terra onde morava e que, a qualquer tempo, poderia deixar aquele lugar.

Portanto, entendendo-se, desde o princípio, a alimentação dos paulistas e sua evolução através da culinária caipira, pode-se estabelecer uma relação: milho, doce, festa junina e cultura caipira.

\subsection{Os doces das festas juninas}

Helena Sangirardi (1983) em seu livro "Alegria de Cozinhar", dedica um capítulo somente a receitas de doces para festas juninas, entre elas canjica, curau, pamonha, pamonha de fubá, bolo de fubá e pipoca doce.

Note-se que o milho enfatiza a comida pertinente a essa festa.

Algumas histórias acompanham essas delícias. Dias Lopes (2014) estabelece que relatos sobre São Paulo no século XIX registraram o enorme apreço dos paulistas pela canjica e tudo o mais que viesse do milho. Era tanto o apreço pela iguaria que muitos a julgavam ser um prato essencialmente paulista.

Canjica, de acordo com Cascudo (2000, p.105) "é prato tradicional indispensável e típico nas festas de São João“.

Segundo Lopes (2014), a palavra canjica designa no Brasil preparações diferentes. Em São Paulo, é uma sopa densa de milho branco, servida fria, às vezes quente, feita com grãos inteiros cozidos em água. No Nordeste, batizam a receita de mungunzá. Alguns acreditam que nos séculos XVI e XVII a canjica foi espalhada pelos bandeirantes, outros acreditam que os índios de são Paulo já a tivessem como comida. Até a origem do nome é controvertida e de acordo com o Dicionário Aurélio, o 
nome provém de Kanjica, da língua dos quimbundos de Angola e foi incorporada na dieta dos negros. Algranti (2011) enfatiza que a canjica era alimento básico dos paulistas cujo preparo foi aprendido com os índios, pois angu e canjica eram pratos básicos da dieta paulista, principalmente na era colonial e especialmente por prescindir do uso do sal.

Outro doce de extrema importância é a pamonha. Para Cascudo (2011), Gilberto Freyre (2012) e Algranti (2000) a pamonha é indígena; a palavra vem do tupi, pamunha e até hoje é um quitute saboreado em quase todas as regiões brasileiras e principalmente a paulista. Pensar e comer pamonha é viajar no tempo e relembrar momentos gostosos de nossa infância. Quem não ralou milho para pamonha ou curau em toda sua vida?

\section{CONSIDERAÇÕES FINAIS}

Diante do exposto neste artigo, pode-se concluir este trabalho sob quatro aspectos que se relacionam entre si: o caipira, o milho, a religiosidade e a festa.

O caipira, o tipo paulista do interior de São Paulo, é a figura centralizadora desses elementos; sem ele e sua cultura não há festa e nem comidas típicas.

A segunda é que todos os autores estudados e principalmente Sergio Buarque de Holanda (1994) estabelecem ser São Paulo a chamada "civilização do milho". Outros autores reforçam a teoria como Antônio Cândido (1975) e Rafaela Basso (2014). Sem o milho, este pequeno grão, a composição alimentar dos paulistas não se constituiria tão representativa.

A terceira consiste na religiosidade do caipira e nas relações de compadrio. Tudo que ele recebia em forma de "graça" é comemorado entre seus pares. Antônio Candido (1975) fala em comunidade de bairro para se referir ao ambiente rural da época do caipira.

E por último a própria festa. Muito embora seja uma festa introduzida pelo europeu e tenha origens europeias, como definido no ínicio do texto, ela se ajusta à figura do caipira no ponto de vista social, da indumentária e da cultura alimentar.
Embora seja uma festa de âmbito nacional, em outros estados como os do Nordeste ela se desconfigura tornando-se algo turístico com mudanças em vestimentas elaboradas; na música e dança incluíram o forró, o xaxado, o baião; os cardápios na festa nordestina se misturaram incluindo bolos de amendoim, cocadas, mungunzá e outras comidas regionais. Já no Sudeste, ela se mantém nas suas origens, as roupas surradas, a música de viola, o linguajar típico do antigo habitante de São Paulo e, sobretudo, a cultura alimentar advinda da civilização do milho, aliás, muito presente no gosto paulista ainda na atualidade tendo restaurantes, como Rancho da Pamonha, Rei do Milho Verde, Castelinho da Pamonha, entre outros, onde encontramos produções exclusivamente à base de milho.

Assim, em um contexto moderno onde o avanço da indústria alimentar e a dissolução de muitas tradições acontecem em nome da rapidez e praticidade, o registro dos saberes alimentares e a manutenção das festas tradicionais visam salvaguardar técnicas e receitas e, principalmente, reconhecer tais práticas como pertencentes a um contexto cultural maior e como uma forma de expressão de um grupo social onde se desenvolve.

Entender a cultura caipira, o seu jeito de ser e ver o mundo, a sua maneira especial de se alimentar e com base nos autores citados, pode-se afirmar que o estado de São Paulo mantém a raiz desta festa tradicional brasileira.

\section{Referências}

ALGRANTI, L.M. À mesa com os paulistas: saberes e práticas culinárias (século XVI - XIX). Disponível em: $<\mathrm{http}: / /$

www.snh2011.anpuh.org/resources/anais/14/1300482 888_ARQUIVO_AMESACOMOSPAULISTAS2versão Anpuh.pdf>. Acesso em 15 jun. 2015. Janeiro: Record, 2000. Pequeno dicionário da gula. Rio de

BASSO, R. A cultura alimentar paulistaา: uma civilização do milho?. São Pauloᄀ: Alameda Casa Editorial, 2014.

BLEIL, S.I. O padrão alimentar ocidental: considerações sobre mudanças de hábitos no Brasil. IN: Cadernos de Debate, vol. VI, 1998. 
BONIN, A.; ROLIM, M.C.M. Hábitos alimentares: tradição e inovação. Boletim de Antropologia. Curitiba, v.4, n-1, p.75-90, jun.1991.

BORNHEIN, G.A. O conceito de tradição. IN: BORNHEIN, G.A. et al. Tradição/Contradição. 2ed. Rio de janeiro: Jorge Zahar/Funarte, 1997.

CANDIDO, A. Os parceiros do Rio Bonito: estudo sobre o caipira paulista e a transformação de seus meios de vida. 3ạ. ed. São Paulo: Livraria Duas Cidades, 1975.

CASCUDO, L.C. Dicionário do folclore brasileiro. 9a․ ed. São Paulo: Global, 2000.

História da Alimentação no Brasil.

3 ed. São Paulo: Global, 2011.

CHIANCA, L. O modo de viver caipira. Disponível em:

<http://www.diplomatique.org.br/artigo.php?id=737> Acesso em 20 jun. 2015.

FREYRE, G. Açúcar: uma sociologia do doce, com receitas de bolos e doces do nordeste do Brasil. São Paulo: Global, 2012.

EMBRAPA. Grão em grão. Jornal eletrônico da Embrapa milho e sorgo (Sete Lagoas-MG), ano 02, edição 7, mai. 2008. Disponível em: <http://www.cnpmsembrapa.br/grao/7_edicao grao_em_grao_materia_03.htm>. Acesso em 15 jun. 2015.

HOLANDA, S.B. Caminhos e fronteiras. 3a. ed. São Paulo: Companhia das Letras, 1994

HOBSBAWN, E.J; RANGER, T. (orgs.). A invenção das tradições. 9ํe ed. São Paulo: Paz e Terra, 2014.

IANNI, O. Uma cidade antiga. Campinas: Ed. Unicamp, 1988.

LOPES, J.A.D. O país das bananas: crônicas e receitas brasileiras. São Paulo: Companhia Editora Nacional, 2014.

MINTZ, S.W. Comida e antropologia: uma breve revisão. Revista Brasileira de Ciências Sociais, rio de Janeiro, v.16,n.47, out.2001.

POULAIN, J. P. Sociologia da alimentação: os comedores e o espaço social alimentar. $2^{\circ} e d$. Florianópolis: Ed. Da UFSC, 2013.

RANGEL, L.H.V. Festas Juninas, Festas de São João: origens, tradição, e história. São Paulo: Publishing Solutions, 2008.

REINHART, J.C. Dize-me o que comes e te direi quem és: alemães, comida e identidade. Curitiba, 2007. Tese de Doutorado em História em Ciências Humanas, Letras e Artes, Universidade Federal do Paraná.
SAINT-HILAIRE, A. Viagem à Província de São Paulo. São Paulo (SP): Livraria Martins, vol. II, 1976. SANCHES, D. G. O modo de vida do caipira em obras de Almeida Júnior. 2ª ${ }^{a}$ ed. Itu (SP): Ottoni Editora, 2011

SANGIRARDI, H. B. Alegria de Cozinhar. Rio de Janeiro: Bloch Editores, 1983

SETUBAL, M. A. Vivências caipiras. São Paulo: Imprensa Oficial do Estado de São Paulo (CEPENC) 2005.

SILVA, P.P. Farinha, feijão e carne seca: um tripé culinário no Brasil colonial. São Paulo: Senac, 2005. 